\title{
Membrane Potential Oscillations in Dorsal Root Ganglion Neurons: Role in Normal Electrogenesis and Neuropathic Pain
}

\author{
Ron Amir, ${ }^{1}$ Martin Michaelis, ${ }^{2}$ and Marshall Devor ${ }^{1}$ \\ ${ }^{1}$ Department of Cell and Animal Biology, Institute of Life Sciences, Hebrew University of Jerusalem, Jerusalem 91904 , \\ Israel, and 2Physiologisches Institut, Christian-Albrechts Universitat, 24098 Kiel, Germany
}

\begin{abstract}
Abnormal afferent discharge originating at ectopic sites in injured primary sensory neurons is thought to be an important generator of paraesthesias, dysaesthesias, and chronic neuropathic pain. We report here that the ability of these neurons to sustain repetitive discharge depends on intrinsic resonant properties of the cell membrane and that the prevalence of this characteristic increases after nerve injury. Recording from primary sensory neurons in excised rat dorsal root ganglia, we found that some cells show subthreshold oscillations in their membrane potential. The amplitude, frequency, and coherence of these oscillations were voltage sensitive. Oscillations gave rise to action potentials when they reached threshold. Indeed, the presence of oscillations proved to be a necessary condition for sustained spiking both at resting membrane potential and
\end{abstract}

on depolarization; neurons without them were incapable of sustained discharge even on deep depolarization. Previous nerve injury increased the proportion of neurons sampled that had subthreshold oscillations, and hence the proportion that generated ectopic spike discharge. Oscillatory behavior and ectopic spiking were eliminated by $\left[\mathrm{Na}^{+}\right]_{0}$ substitution or bath application of lidocaine or tetrodotoxin (TTX), under conditions that preserved axonal spike propagation. This suggests that a TTX-sensitive $\mathrm{Na}^{+}$conductance contributes to the oscillations. Selective pharmacological suppression of subthreshold oscillations may offer a means of controlling neuropathic paraesthesias and pain without blocking afferent nerve conduction.

Key words: dorsal root ganglion; ectopic firing; paraesthesias; neuropathic pain; subthreshold oscillations; rat
Nerve injury is frequently followed by paraesthesias, dysaesthesias, and severe pain. These "neuropathic" symptoms are poorly responsive to existing analgesic drugs, and represent a major unsolved health problem (Sunderland, 1978; Bonica, 1990). An important generator of neuropathic pain is thought to be abnormal discharge that develops at ectopic (i.e., abnormal) sites in some injured sensory neurons (Nordin et al., 1984; Kuslich et al., 1991; Devor, 1994; Xie et al., 1995; Study and Kral, 1996). This ectopic discharge appears to directly evoke ongoing paraesthesias and pain. In addition, it may also trigger and maintain "central sensitization," a CNS hyperexcitability state in which normally non-noxious input carried on large myelinated $\mathrm{A} \beta$ touch afferents is felt as painful (allodynia) (Woolf, 1983; Campbell et al., 1988). Both ongoing pain and allodynia are eliminated by preventing ectopic discharge from gaining access to the CNS (Gracely et al., 1992; Sheen and Chung, 1993).

It is generally presumed that ectopic neuropathic discharge results from the classical (Hodgkin-Huxley) repetitive firing process whereby a sustained depolarization repeatedly draws the membrane potential toward threshold (Jack et al., 1985). We now report evidence that the discharge in fact results from a quite different process. Recording from rat dorsal root ganglia (DRGs) in vitro we found that a considerable proportion of primary

\footnotetext{
Received April 27, 1999; revised June 11, 1999; accepted July 12, 1999.

This work was supported by the United States-Israel Binational Science Foundation (BSF), the German-Israel Foundation for Research and Development (GIF), and the Leopold, Norman and Sara Yisraeli Memorial Fund. M.M. received a Heisenberg fellowship from the Deutsche Forschungsgemeinschaft. We thank B. Hutcheon for helpful comments on this manuscript.

Correspondence should be addressed to Professor Marshall Devor, Department of Cell and Animal Biology, Institute of Life Sciences, Hebrew University of Jerusalem, Jerusalem 91904, Israel.

Copyright (C) 1999 Society for Neuroscience $\quad 0270-6474 / 99 / 198589-08 \$ 05.00 / 0$
}

sensory neurons of specific types show sinusoidal voltage oscillations in their membrane potential. Ectopic spikes generated in these DRG neurons always emerged from the rising phase of the sinusoids and hence appear to be triggered by the oscillations. DRG neurons without oscillations were unable to generate sustained discharge even when deeply depolarized, indicating that the oscillatory process is a necessary condition for repetitive firing in this type of neuron.

Chronic nerve injury, a condition associated with enhanced TTX-sensitive $\mathrm{Na}^{+}$conductance (Rizzo et al., 1996; Study and Kral, 1996; Cummins and Waxman, 1997), was found to increase the prevalence of neurons exhibiting subthreshold oscillations and consequently the magnitude of the resulting ectopic discharge. On the other hand, partial substitution of $\mathrm{Na}^{+}$ions in the bath, or bath application of low concentrations of lidocaine or TTX, eliminated the oscillations, and with them the ectopic discharge. This occurred at times when impulse propagation along the afferent axons was spared. These observations suggest that pharmacological agents capable of suppressing the oscillatory process in primary afferent neurons should suppress ectopic discharge and associated neuropathic symptoms.

\section{MATERIALS AND METHODS}

Immature (22-88 gm, 2-5 weeks of age) and adult (165-530 gm) male and female rats of the Wistar-derived Sabra strain were deeply anesthetized (Nembutal, CEVA, Paris, France; $>60 \mathrm{mg} / \mathrm{kg}$, i.p) and killed by carotid exsanguination. DRGs L4 and L5 with the dorsal root (DR) and a variable length of the spinal/sciatic nerve attached were excised. In some adult animals the sciatic nerve was tightly ligated with 5-0 silk and cut just distal to the ligature $2-15 \mathrm{~d}$ before excision. All work adhered to national, university, and International Association for the Study of Pain guidelines for the humane care and use of laboratory animals. After $\sim 1$ $\mathrm{hr}$ recovery in a modified Krebs solution containing (in mM): $\mathrm{NaCl} 124$, $\mathrm{NaHCO}_{3} 26, \mathrm{KCl} 3, \mathrm{NaH}_{2} \mathrm{PO}_{4} 1.3, \mathrm{MgCl} 2$, dextrose 10, and saturated 
with $95 \% \mathrm{O}_{2}$ and 5\% $\mathrm{CO}_{2}, \mathrm{pH} 7.4$ (290-300 mOsm, room temperature), the tissue was mounted in a recording chamber and superfused with the Krebs solution $\left(1-2 \mathrm{ml} / \mathrm{min}\right.$, room temperature or $\left.37^{\circ} \mathrm{C}\right)$ to which $2 \mathrm{~mm}$ $\mathrm{CaCl}_{2}$ was added. In some experiments in adult rats, the $124 \mathrm{~mm} \mathrm{NaCl}$ in the bath was replaced with $124 \mathrm{~mm}$ choline-Cl (Sigma, St. Louis, MO). The recording chamber was set on a massive table top isolated from external vibrations by air suspension (Micro-g, Technical Manufacturing, Peabody, MA.)

The DRG capsule was slit open in ganglia from mature rats but left intact in ganglia taken from immature rats. Sharp glass microelectrodes were used for intracellular recording and stimulation (20-40 M $\Omega$ filled with $3 \mathrm{M} \mathrm{KCl}$ ) of DRG neurons. Intracellular stimuli were either brief steps $(1 \mathrm{msec})$, prolonged steps ( $\sim 80 \mathrm{msec}$ to $>2 \mathrm{sec})$, or ramp-and-hold stimuli (rise time $2 \mathrm{sec}>\tau>0.1 \mathrm{sec}$, hold $>2 \mathrm{sec}$ ). Axonal stimuli, applied to the nerve through an $\mathrm{Ag} / \mathrm{AgCl}$ electrode pair, were monophasic, $0.1-0.2 \mathrm{msec}$ square pulses, $\leq 7 \mathrm{~mA}$. The evoked compound action potential was monitored on the DR through a recording suction electrode and served as an indicator of spike propagation through the ganglion. Resting membrane potential was more negative than $-40 \mathrm{mV}$, and on single-pulse intracellular (somatic) or axonal stimulation there was always an overshooting spike.

DRG neurons were categorized by axon conduction velocity $(\mathrm{CV})$ and the shape of the intracellularly recorded spike. Briefly, we took the axon to be myelinated (A-neuron) if $\mathrm{CV} \geq 1 \mathrm{~m} / \mathrm{sec}$. Cells with $\mathrm{CV}<1 \mathrm{~m} / \mathrm{sec}$ were designated as having nonmyelinated axons (C-neurons). In the few cases in which $\mathrm{CV}$ was not established, cells were assumed to be A-neurons if they had no inflection on the falling phase of the spike and/or spike width $<2 \mathrm{msec}$ at one-half peak-to-peak amplitude. A-neurons were further categorized on the basis of whether the spike evoked by intracellular or axonal stimulation was narrow and lacked an inflection of its falling phase $\left(\mathrm{A}_{0}\right.$-neurons) or whether they were broader and had an inflection ( $\mathrm{A}_{\mathrm{INF}}$-neuron) (Koerber and Mendell 1992; Amir and Devor 1996; Villiere and McLachlan 1996). A circuit that calculated the spike waveform derivative was used for this purpose.

Membrane potential was sampled at $5 \mathrm{kHz}$ for $1-4 \mathrm{sec}$ (pCLAMP v6.0.3, Axon Instruments, Foster City, CA) and processed by fast Fourier analysis (FFT) and autocorrelation using DataWave software (CP Analysis v5.1). All mean values are given \pm SD.

\section{RESULTS}

\section{DRGs from intact animals}

When first penetrated, most DRG neurons in young rats had a stable resting potential. A minority, however, exhibited periodic, sinusoidal membrane potential oscillations (9/73 A-neurons sampled, $12.3 \%$ ), with a mean frequency of $96 \pm 18 \mathrm{~Hz}$ (range $78-127$ $\mathrm{Hz}$ ). Membrane potential oscillations were usually sustained, but in some cells there were intermittent brief pauses $(\leq 100 \mathrm{msec})$. The small amplitude of the oscillations at resting membrane potential (1.4 $\pm 0.6 \mathrm{mV}$ peak-to-peak), and their high frequency, may explain why they have not been reported previously (also see Discussion). Once one is alerted to their presence, the oscillations are readily distinguished in raw recordings and documented using Fourier analysis or autocorrelation (Fig. 1). The presence or absence of oscillations in any given neuron was usually unequivocal. However, we adopted as a formal criterion that amplitude peaks be at least $1.5 \times$ the amplitude of the background noise level seen during brief pauses when present, and/or that there be a distinct peak in the FFT plot at the frequency expected from visual inspection of the voltage trace.

The resting potential of cells that had subthreshold oscillations on initial electrode penetration was more depolarized, on average, than that of cells without oscillations $(-49.4 \pm 6.4 \mathrm{mV}$ vs $-60.5 \pm 6.5 \mathrm{mV}, p<0.01)$. Correspondingly, depolarization by intracellular current injection recruited oscillations in some neurons in which they were not detected on initial penetration (Fig. 1, Table 1) and reduced the prevalence of silent pauses in cells that had oscillations at rest. For example, measurements in five intermittent cells showed an increase in the percentage of time oscillating from $68 \%$ at rest to $91 \%$ when depolarized by $8 \mathrm{mV}$. Therefore, to assess whether a cell had oscillatory capability, we routinely shifted the membrane potential in the depolarizing direction until the appearance of oscillations as defined above, or until the membrane potential reached $-20 \mathrm{mV}$. With use of this search protocol the number of A-neurons with oscillations more than doubled from that seen at resting potential, and oscillations were revealed in $\mathrm{C}$-neurons (Table 1 ).

Nearly all of the A-neurons that had subthreshold oscillations were of the $\mathrm{A}_{0}$ type, i.e., they were A-neurons lacking an inflection (Table 1). Oscillations were encountered in only one $\mathrm{A}_{\mathrm{INF}^{-}}$ neuron. In general, $\mathrm{A}_{0}$-neurons tend to be low-threshold mechanoreceptors, whereas $\mathrm{A}_{\mathrm{INF}^{-}}$and $\mathrm{C}$-neurons include many nociceptors (Koerber and Mendell, 1992).

Fourier analysis revealed that subthreshold oscillations in any given neuron form a monotonic frequency peak, the cell's "dominant oscillation frequency." The dominant frequency gradually increased as the cell was depolarized. As the frequency increased, the width of the frequency power distribution narrowed and its height increased, reflecting a voltage-dependent increase in the amplitude and coherence of the oscillations (Fig. 1). With further depolarization, oscillation frequency continued to increase, but the amplitude declined until oscillations were no longer discernible. It was therefore possible to define a "best oscillation frequency" at which the oscillation amplitude was maximal. Peak oscillation amplitude usually fell within the range of 3-6 mV. Best frequency for $\mathrm{A}_{0}$-neurons averaged $118 \pm 26 \mathrm{~Hz}(88-195 \mathrm{~Hz}, n=$ 20) and for C-neurons $11.7 \pm 2.9(10-15 \mathrm{~Hz}, n=3)$. Determination of these values was often complicated by the appearance of spike discharge (see below).

To ascertain whether subthreshold oscillations are a peculiarity of sensory neurons in young animals, we also looked at neurons in DRGs taken from adult rats. Both $\mathrm{A}_{0^{-}}$and $\mathrm{C}$-neurons in adults showed sinusoidal oscillations very similar to those seen in young animals. The prevalence of $\mathrm{A}_{0}$-neurons with subthreshold oscillations at rest or on depolarization was higher in immature than in adult rats (35 vs $11 \%, p=0.002)$ (Tables 1,3$)$. In C-neurons, on the other hand, it was slightly higher in adults, although the difference was not statistically significant ( 25 vs $28 \%, p>0.2$ ). In all cases, the amplitude, frequency, and prevalence of the oscillations were dependent on membrane potential much as in immature animals. Best frequency for $\mathrm{A}_{0}$-neurons in adults averaged $124 \pm 44 \mathrm{~Hz}(68-195 \mathrm{~Hz}, n=6)$ and for $\mathrm{C}$-neurons averaged $52 \pm 35(15-107 \mathrm{~Hz}, n=6)$.

\section{Repetitive spike discharge}

In DRGs from both immature and adult rats, repetitive spike discharge was rare at resting membrane potential. However, on injection of depolarizing current, either by a step function or a slow ramp, a significant proportion of the cells began to discharge repetitively (Table $2 ; \chi^{2} p<0.001$ ). Depolarization promoted spiking in two ways: it increased oscillation amplitude, and it brought the neuron closer to spike threshold.

There was a striking relation between the presence of subthreshold potential oscillations and repetitive firing. Only neurons that showed oscillations fired repetitively at rest or on depolarization. Moreover, in all neurons that fired repetitively, action potentials consistently emerged from the rising (depolarizing) phase of oscillations. This indicates a causal relation between the oscillations and spiking, not just a correlation (Figs. 1B, 2). The site of spike initiation would appear to be close to the recording electrode, presumably at the axon hillock-initial segment portion 
A

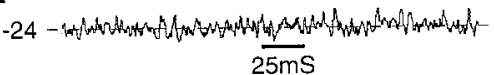

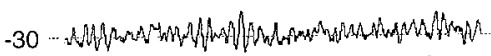

$$
\begin{aligned}
& 12 \mathrm{mV}
\end{aligned}
$$

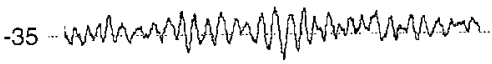

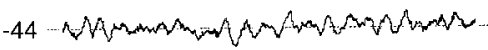

$$
\begin{aligned}
& -50 \quad \mathrm{Vr}
\end{aligned}
$$
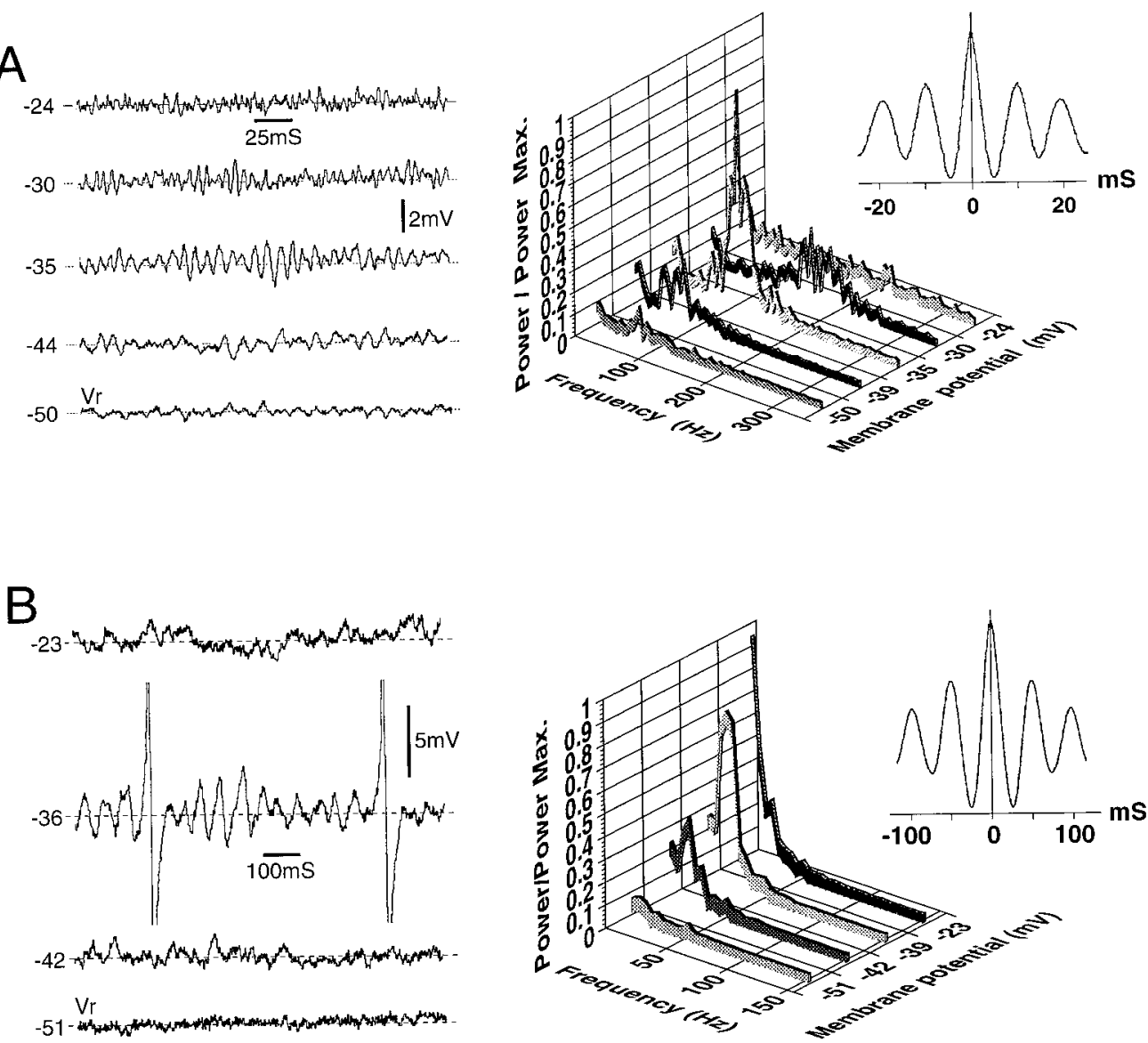

Figure 1. Membrane potential oscillations recorded from DRG A- and C-neurons. $A$, Subthreshold oscillations recorded from an $\mathrm{A}_{0}$-neuron in an immature rat with nerves intact. Oscillation amplitude was increased when the cell was depolarized from rest $\left(V_{\mathrm{r}}\right)$ to $-35 \mathrm{mV}$ and subsequently decreased with still deeper depolarization (left). This neuron did not fire action potentials. The FFT profile in this cell illustrates oscillation coherence and amplitude (power) peak $(103 \mathrm{~Hz})$ at $-35 \mathrm{mV}$ and the increase in oscillation frequency with depolarization (right). Power scale was normalized relative to the maximal power recorded at $-35 \mathrm{mV}$. The inset shows the autocorrelogram at $-35 \mathrm{mV}$. B, Membrane oscillations recorded from a C-neuron in a mature rat $15 \mathrm{~d}$ after sciatic injury. At $-36 \mathrm{mV}$, oscillations occasionally triggered action potentials [spike amplitude is truncated (left)]. The FFT profile at different membrane potentials in this cell, and its autocorrelogram (inset), illustrates a dominant oscillation frequency of $20 \mathrm{~Hz}$ at $-39 \mathrm{mV}$ (right). The power scale was normalized as in $A$.

\begin{tabular}{|c|c|c|c|}
\hline $\begin{array}{l}\text { Type of } \\
\text { neuron }\end{array}$ & $\begin{array}{l}\text { Resting membrane } \\
\text { potential }(\mathrm{mV}, \text { mean } \pm \mathrm{SD})\end{array}$ & $\begin{array}{l}\text { Cells with subthreshold } \\
\text { oscillations at resting } \\
\text { potential }\end{array}$ & $\begin{array}{l}\text { Cells with subthreshold } \\
\text { oscillations when } \\
\text { depolarized }\end{array}$ \\
\hline A-neurons & $-59.4 \pm 7.8$ & $9 / 73(12.3 \%)$ & $20 / 73(27.4 \%)^{a}$ \\
\hline $\mathrm{A}_{0}$ & $-58.6 \pm 7.6^{b}$ & $9 / 54(16.7 \%)$ & $19 / 54(35.2 \%)^{a}$ \\
\hline $\mathrm{A}_{\mathrm{INF}}$ & $-61.4 \pm 7.9$ & $0 / 19(0 \%)$ & $1 / 19(5.7 \%)$ \\
\hline C-neurons & $-67.4 \pm 5.7$ & $0 / 12(0 \%)$ & $3 / 12(25 \%)$ \\
\hline
\end{tabular}

${ }^{a}$ Resting potential versus depolarized: $p<0.05$ (two-tailed $\chi^{2}$ test).

$b_{-} 49.4 \pm 6.4 \mathrm{mV}$ in the nine cells with oscillations at rest (see Results).

of the cell soma. Cells that did not show subthreshold oscillations never fired repetitively, either spontaneously or on ramp depolarization $(n=165)$, and although some did fire a single spike or a short burst of spikes at the beginning of a step depolarization, none generated discharge that lasted $>200 \mathrm{msec}$, the criterion that we adopted for "repetitive firing."

Two patterns of repetitive discharge were observed in neurons with oscillatory capability: slow and irregular ( $0.5-4 \mathrm{imp} / \mathrm{sec})$, and bursty (Table 2). In neurons that fired irregularly, single spikes occurred when individual oscillations reached threshold. In bursting cells, oscillations that reached threshold triggered a burst of high-frequency spikes (interspike interval 4-15 msec). Bursts were usually terminated by a burst-induced hyperpolarizing shift of the membrane potential (Amir and Devor, 1997). After firing stopped, subthreshold oscillations could once again be observed, but their amplitude was lower than it was before the burst. As the hyperpolarizing shift faded the amplitude of the oscillations increased. Eventually one oscillation reached threshold and evoked 
Table 2. Prevalence of spike discharge and discharge patterns (bursting vs slow irregular firing)

\begin{tabular}{|c|c|c|c|c|}
\hline \multirow[b]{2}{*}{ Type of neuron } & \multicolumn{2}{|c|}{ Immature rats } & \multicolumn{2}{|c|}{ Adult rats } \\
\hline & Bursts & Irregular & Bursts & Irregular \\
\hline \multicolumn{5}{|l|}{$\mathrm{A}_{0}$-neurons } \\
\hline At resting potential & $1 / 54$ & $2 / 54$ & $1 / 80$ & $0 / 80$ \\
\hline Depolarized & $10 / 54$ & $2 / 54$ & $8 / 80^{a}$ & $0 / 80$ \\
\hline \multicolumn{5}{|l|}{$\mathrm{A}_{\mathrm{INF}}$-neurons } \\
\hline At resting potential & $0 / 19$ & $0 / 19$ & $0 / 15$ & $0 / 15$ \\
\hline Depolarized & $0 / 19$ & $0 / 19$ & $0 / 15$ & $1 / 15$ \\
\hline \multicolumn{5}{|l|}{ C-neurons } \\
\hline At resting potential & $0 / 12$ & $0 / 12$ & $0 / 25$ & $0 / 25$ \\
\hline Depolarized & $0 / 12$ & $0 / 12$ & $0 / 25$ & $3 / 25^{b}$ \\
\hline
\end{tabular}

${ }^{a}$ In one of these eight neurons firing was tonic (i.e., without interruptions).

${ }^{b}$ One of these three neurons shifted from irregular to tonic firing (at $15 \mathrm{imp} / \mathrm{sec}$ ) when deeply depolarized.

a second burst of spikes, completing the burst cycle (Fig. 2). The on-off duty cycle of bursts ranged from $0.02-1 \mathrm{sec}$ on/0.05-4 sec off and varied with membrane potential. Both the bursty and the slow/irregular ectopic discharge pattern have been described previously in DRG neurons in vivo (Wall and Devor, 1983).

\section{DRGs from nerve-injured animals}

We next investigated the effect of previous nerve injury on membrane potential oscillations and on the ectopic spike discharge that they trigger. The sciatic nerve was transected in adult rats, and DRG recordings were made $2-15 \mathrm{~d}$ later. This form of nerve injury is known to induce both ongoing pain in the area of denervation, and allodynia in the adjacent partially denervated territory (Wall et al., 1979; Markus et al., 1984; Kingery and Vallin 1989). We found that nerve injury induced a significant increase in the prevalence of DRG neurons with subthreshold oscillations, at least in $\mathrm{A}_{0}$-neurons (Table 3 ). The proportion of $\mathrm{A}_{0}$-neurons with oscillations at rest or on depolarization increased from 11 to $46 \%$ ( $p<0.0002)$. In $\mathrm{C}$-neurons the proportion increased from 28 to $44 \%$, although this difference did not reach statistical significance $(p>0.2)$. As a consequence of the increased incidence of oscillations, the incidence of repetitive spike discharge also increased (Table 3).

\section{Oscillatory mechanism}

A voltage- and TTX-sensitive $\mathrm{Na}^{+}$conductance(s) appears to contribute to the resonance characteristic responsible for subthreshold membrane potential oscillations in DRG neurons. As illustrated in Figure 3, partial replacement of $\mathrm{Na}^{+}$in the bath solution with choline eliminated the oscillations $\left(5 / 5 \mathrm{~A}_{0}\right.$-cells tested), as did bath application of either TTX (Sigma; $1 \mu \mathrm{M}, 4 / 4$ $\mathrm{A}_{0}$-cells tested, and $3 / 3 \mathrm{C}$-cells tested) or lidocaine (Teva, Tel Aviv, Israel; $\geq 4 \mu \mathrm{M}, 5 / 5 \mathrm{~A}_{0}$-cells tested, 1/1 C-cells tested). Once eliminated in this way, oscillations could not be restored by further depolarization, but they generally reappeared after washout of the blocker (Fig. 3). At $1 \mu \mathrm{M}$, TTX effectively distinguishes between TTX-sensitive and TTX-resistant $\mathrm{Na}^{+}$channels (Sangameswaran et al., 1996). Bath-applied $\mathrm{Co}^{2+}$ (5 mM), a wide-spectrum $\mathrm{Ca}^{2+}$ channel blocker, was not effective at blocking the oscillations (up to $6 \mathrm{~min}$ ).

Suppression of oscillations with $\mathrm{Na}^{+}$substitution, TTX, or lidocaine always suppressed repetitive firing, consistent with the idea of a causative relation between the oscillations and the firing (8/8 discharging $\mathrm{A}_{0}$-cells and 2/2 C-cells tested) (Fig. 3). Inter- estingly, oscillations and consequent firing were consistently blocked at times when propagation of spikes evoked by axonal stimulation persisted (Fig. 3). At high concentrations of lidocaine (0.4-40 mM), spike propagation was blocked along with the oscillations, but at low concentrations $(4 \mu \mathrm{M})$, oscillations were eliminated and spike propagation persisted ( $4 / 4 \mathrm{~A}_{0}$-neurons). The same occurred using low- $\mathrm{Na}^{+}$Krebs solution. In both cases spike height was attenuated. TTX $(1 \mu \mathrm{M})$ blocked oscillations and repetitive spiking rapidly, and propagation only after a delay. Ectopic firing in vivo is also suppressed using lidocaine concentrations insufficient to block axon conduction (Devor et al., 1992).

\section{Potential electrical and mechanical artifacts}

Various neuronal types in the CNS are known to have intrinsic oscillatory properties (Llinas, 1988; Yarom, 1989; Alonzo and Klink, 1993; Puil et al., 1994; Gutfreund et al., 1995; Hutcheon et al., 1996). However, we know of no previous reports of sustained oscillations in DRG somata despite the abundant attention these cells have attracted. The main reason, as noted above, is probably the relatively small proportion of neurons (in intact ganglia) that show oscillations at resting membrane potential, and their small amplitude. Nonetheless, it is prudent to consider the possibility that our findings are the result of an electrical or mechanical artifact.

An explanation based on artifactual electrical pickup can be excluded because the oscillation rate was not a multiple of the 50 $\mathrm{Hz}$ line current, and frequency, amplitude, and coherence of oscillations were voltage and drug sensitive. Moreover, their prevalence within a particular ganglion depended on cell type and previous axotomy. We can also rule out an error based on mechanical vibrations in the recording system, both crude movement artifact and the more esoteric possibility of vibration-evoked ionic currents attributable to coupling between mechanosensitive channels and a TTX-sensitive $\mathrm{Na}^{+}$conductance. First, the recording system was isolated from building vibrations by a high quality air suspension table. Second, the oscillation frequency was sensitive to membrane potential and varied from cell to cell within a ganglion (Fig. 1). Third, identical results were obtained using two separate micromanipulator systems that had different inertial mass ( 700 vs $1500 \mathrm{~g}$ ) and hence different mechanical resonances. Fourth, the intrinsic resonance frequency of our main micromanipulator-microelectrode system, determined by dropping graded weights on the table during the course of recording, was $\sim 20 \mathrm{~Hz}$, and not $\sim 100 \mathrm{~Hz}$ like the subthreshold oscillations. Moreover, the $20 \mathrm{~Hz}$ oscillations generated in this way did not vary with cell type and occurred even when the microelectrode was extracellular. Finally, there is no obvious mechanism that would have immunized the authors of previous studies of DRG neurons from artifacts caused by voltage- and ligand-sensitive conductances coupled to putative mechanosensitive channels.

\section{DISCUSSION}

We have shown that some $\mathrm{A}_{0^{-}}$and $\mathrm{C}$-neurons in rat DRGs display sinusoidal voltage-sensitive oscillations in their membrane potential, that these oscillations give rise to action potentials when they reach threshold, and that oscillations are an essential requirement for the generation of sustained spike discharge on steady-state or slow-ramp depolarization. Nerve injury increases the prevalence of oscillations and consequently the intensity of ectopic discharge originating in the DRG.

Although subthreshold oscillations and resonance have not been reported previously in DRG neurons, they have been de- 


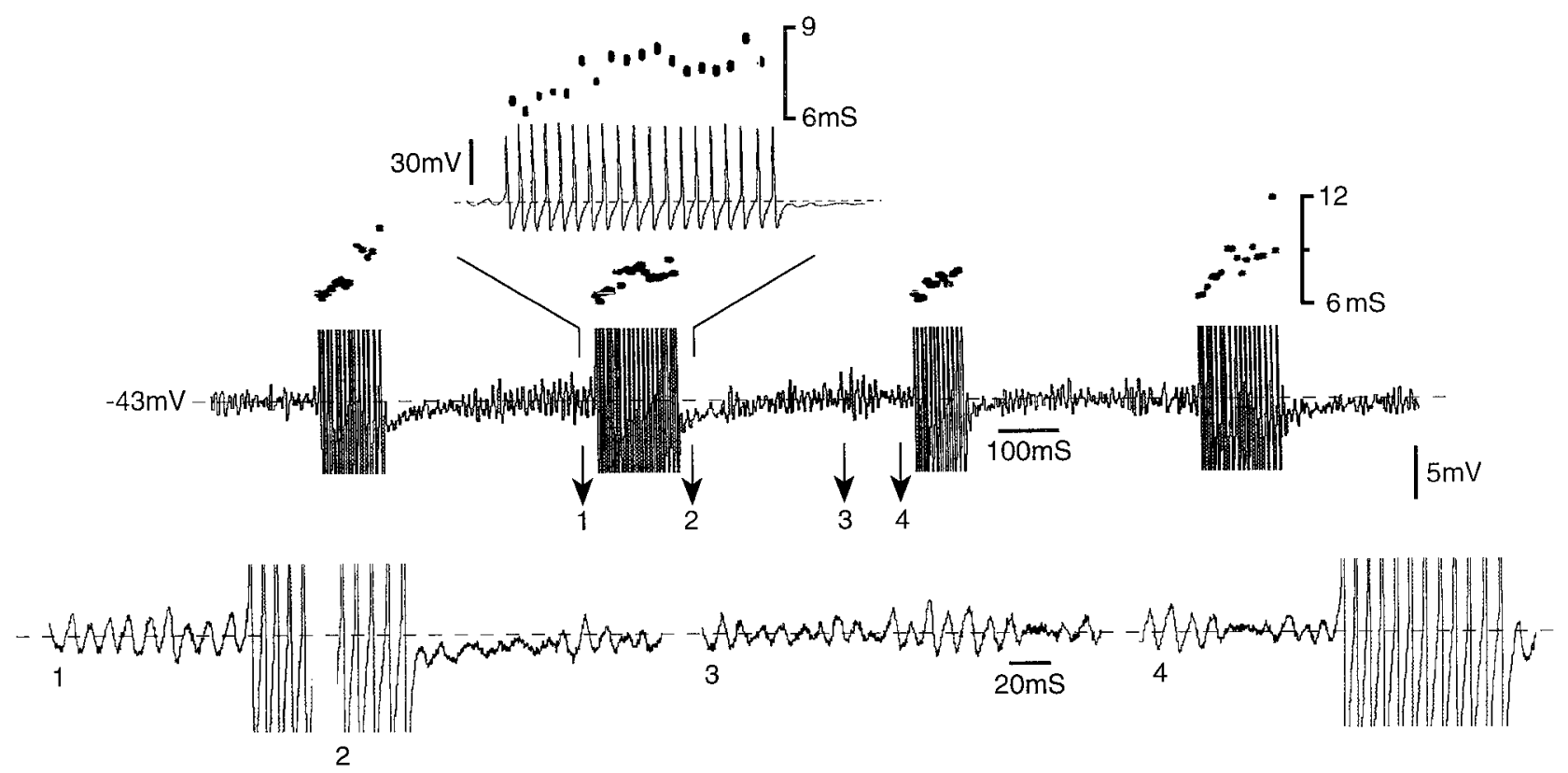

Figure 2. Spontaneous repetitive bursty discharge in a DRG $\mathrm{A}_{0}$-neuron from an immature rat. Spikes are truncated except in the inset at top, which shows one of the bursts on a faster timebase. The interspike interval dot display above each of the four spike bursts shown illustrates the gradual deceleration of discharge during the course of the burst. A similar firing pattern is seen in in vivo recordings of ectopic burst discharge originating in the DRG. Segments of the record at time points 1-4 are shown below on a still faster timebase to illustrate the triggering of spike bursts by membrane potential oscillations.

Table 3. Effect of previous sciatic nerve injury on the proportion of DRG neurons in adult rat DRGs that had membrane potential oscillations and produced repetitive spike discharge (firing)

\begin{tabular}{lll} 
Type of neuron & Intact rats & Nerve-injured rats \\
\hline $\mathrm{A}_{0}$-neurons & & \\
At resting potential & $1 / 80(1.3 \%)$ & $4 / 35(11.4 \%)^{*}$ \\
& Firing: 1 & Firing: 3 \\
& $9 / 80(11.3 \%)$ & $16 / 35(45.7 \%)^{* *}$ \\
Depolarized & Firing: 8 & Firing: $15^{* *}$ \\
& & \\
$\mathrm{~A}_{\mathrm{INF}}$-neurons & $0 / 15(0 \%)$ & $0 / 19(0 \%)$ \\
At resting potential & Firing: 0 & Firing: 0 \\
& $1 / 15(6.7 \%)$ & $0 / 19(0 \%)$ \\
Depolarized & Firing: 1 & Firing: 0 \\
& & \\
C-neurons & $0 / 25(0 \%)$ & $0 / 41(0 \%)$ \\
At resting potential & Firing: 0 & Firing: 0 \\
& $7 / 25(28.0 \%)$ & $18 / 41(43.9 \%)$ \\
Depolarized & Firing: 3 & Firing: 11
\end{tabular}

Firing occurred only in cells with oscillations. Intact versus nerve-injured: ${ }^{*} p<0.05$; ${ }^{* *} p<0.001$ (two-tailed $\chi^{2}$ test).

scribed in primary sensory neurons in the trigeminal system. Pelkey and Marshall (1998) recently reported sustained, highfrequency, voltage-sensitive oscillations in some neurons of the mesencephalic nucleus of the trigeminal nerve (MesV). Puil and coworkers (Puil et al., 1986, 1988, 1989; Puil and Spigelman 1988) showed that trigeminal ganglion (TRG) neurons, when stimulated with a sinusoidally varying constant current waveform, show a voltage maximum at particular resonant frequencies. No spontaneous subthreshold oscillations were seen, although transient damped oscillations occurred during step depolarization. In both the MesV and TRG, oscillatory behavior was usually between 100 and $180 \mathrm{~Hz}$, frequencies similar to those seen in DRG $\mathrm{A}_{0}$-neurons.

\section{Conductances involved in subthreshold oscillations}

As in TRG neurons, oscillatory tendency in DRG neurons is probably an intrinsic property of the neuron itself. The conductances thought to underlie oscillations in brainstem, thalamic, and cortical neurons (low-threshold $\mathrm{Ca}^{2+}, \mathrm{Ca}^{2+}$-activated $\mathrm{K}^{+}, \mathrm{I}_{\mathrm{O}}$, $\mathrm{IK}_{\mathrm{S}}$, and $\mathrm{I}_{\mathrm{H}}$ ) are generally too slow, and/or operate in voltage ranges too negative, to account for the oscillatory behavior we saw in primary afferents (Llinas, 1988; Yarom, 1989; Alonzo and Klink, 1993; Puil et al., 1994; Gutfreund et al., 1995; Hutcheon et al., 1996). An interaction of voltage-sensitive $\mathrm{Na}^{+}$channels and $\mathrm{K}^{+}$or leak channels, as in the squid giant axon (Guttman and Barnhill, 1972), is a more likely mechanism (see below). Oscillatory behavior can also emerge from network properties of functionally coupled neurons (Selverston, 1985; Getting, 1989; Yarom, 1989). Although DRGs are essentially devoid of synaptic interconnections, DRG cells are weakly coupled by extracellular $\mathrm{K}^{+}$and diff usible chemical mediators (Utzschneider et al., 1992; Amir and Devor, 1996). However, these nonsynaptic coupling processes are too sluggish to account for the high-frequency oscillations of DRG neurons.

The experiments using ion substitution and pharmacological blockers suggest a central role for one or more TTX- and lidocaine-sensitive $\mathrm{Na}^{+}$channels in the generation of the depolarizing limb of subthreshold oscillations. The repolarizing limb is probably caused by an outward $\mathrm{K}^{+}$or leak conductance (Llinas, 1988). For example, Hudspeth and collaborators (Roberts et al., 1988) have identified a large-conductance $\mathrm{Ca}^{2+}$ activated $\mathrm{K}^{+}$channel $\left(\mathrm{K}_{\mathrm{Ca}}\right)$ as essential for the repolarizing phase of subthreshold oscillations in cochlear hair cells. In studies to be reported elsewhere, we applied the $\mathrm{K}^{+}$channel blockers 4-aminopyridine (Sigma; $1.0 \mathrm{~mm}$ ) or tetraethyl ammonium extra- 

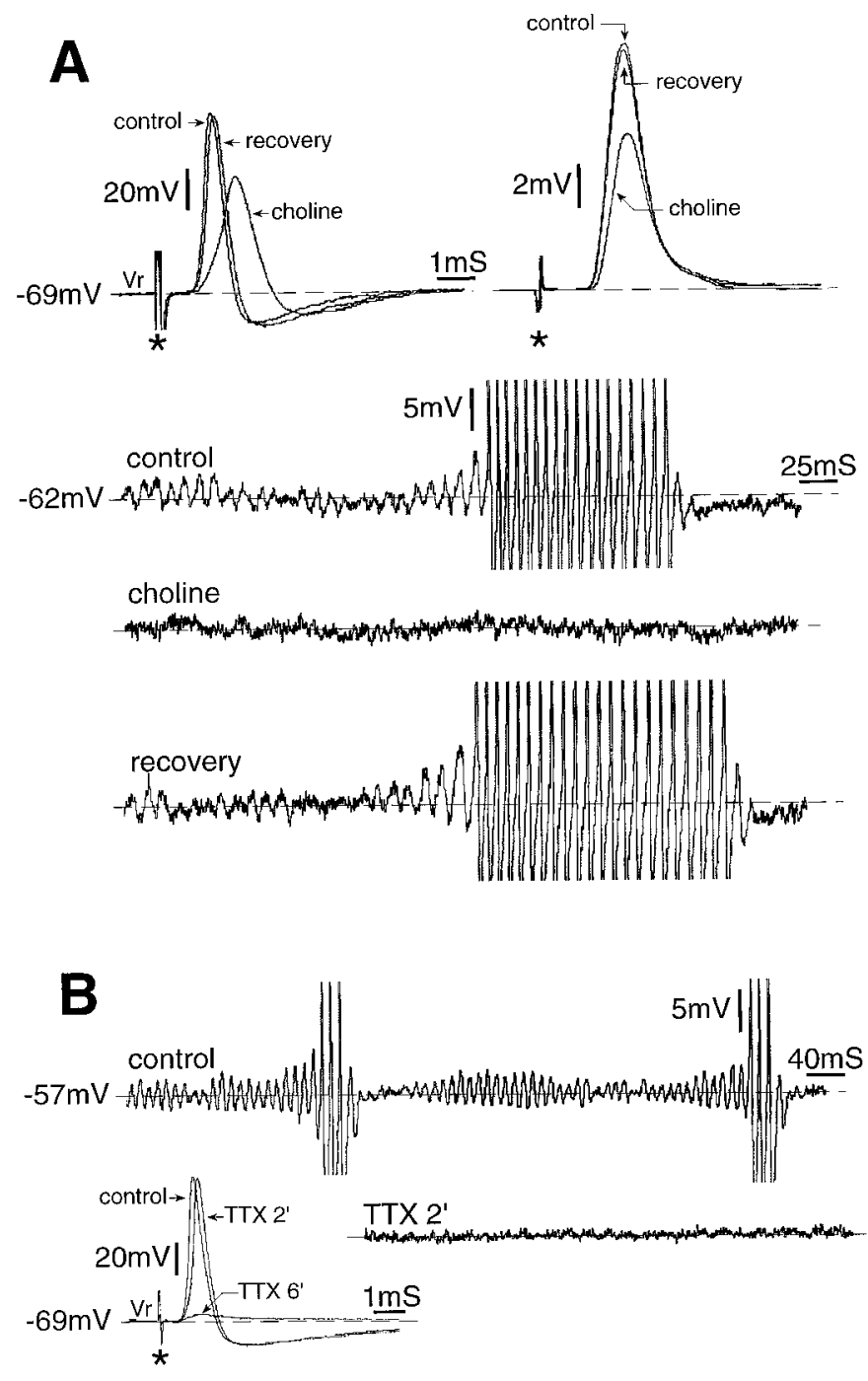

Figure 3. Subthreshold membrane potential oscillations, and resulting spike bursting, depend on voltage-sensitive $\mathrm{Na}^{+}$conductance. $A$ illustrates a period of subthreshold oscillations that lead up to a spike burst in an $\mathrm{A}_{0}$-neuron from an adult rat whose ipsilateral sciatic nerve had been cut $7 \mathrm{~d}$ previously (control). Replacing $\mathrm{NaCl}$ in the bath solution with choline-Cl, thus reducing the bath $\mathrm{Na}^{+}$concentration from 151 to $27 \mathrm{mM}$, abolished the oscillations and the resulting spikes within 2 min. They could not be restored by further depolarization. Washout of choline and return to the control bath solution restored both the oscillations and bursting within 17 min (recovery). All three traces were recorded at $-62 \mathrm{mV}$. Top traces show (left) the intracellularly recorded spike before, during, and after choline application [at resting potential $\left(V_{\mathrm{r}}\right)=-69 \mathrm{mV}$ ], and (right) the simultaneously recorded DR compound action potential. Both spike and compound action potential persisted, if with a reduced amplitude, when oscillations and ectopic spiking were eliminated. Propagation distance from the sciatic nerve stimulation site was $37 \mathrm{~mm}$ to the cell soma and $50 \mathrm{~mm}$ to the compound action potential recording electrode. $B$, In this $\mathrm{A}_{0}$-neuron from an adult rat DRG, depolarization from rest $\left(V_{\mathrm{r}}=-69 \mathrm{mV}\right)$ to $-57 \mathrm{mV}$ yielded subthreshold oscillations that triggered spike bursting (control trace; spikes truncated). Bath application of $1 \mu \mathrm{M}$ TTX abolished the oscillations and spikes within $2 \min \left(T T X 2^{\prime}\right)$. Spike propagation in response to nerve stimulation at a distance of $7 \mathrm{~mm}$ persisted at this time, although it failed $4 \mathrm{~min}$ later $\left(T T X 6^{\prime}\right)$. Further depolarization failed to restore oscillations or spiking, but TTX washout frequently did (data not shown).

cellularly (Sigma; $10 \mathrm{~mm}$ ) or $\mathrm{Cs}^{2+}$ intracellularly. However, this did not eliminate the oscillations. Indeed, these blockers augmented oscillatory behavior and induced ectopic spiking, consistent with their excitatory effect in vivo (Devor 1983). $\mathrm{Ca}^{2+}$ channel blockers also appear to be ineffective [see Results and
Matzner and Devor (1994)]. We tentatively conclude that in the DRG the inward depolarizing TTX-sensitive $\mathrm{Na}^{+}$current interacts with a nonspecific repolarizing leak conductance to generate oscillations. DRG neurons are highly heterogeneous in the spectrum of ion channels that they express. The ultimate explanation of why $\mathrm{A}_{0}$-neurons are oscillatory and $\mathrm{A}_{\mathrm{INF}}$-neurons generally are not is presumably related to this heterogeneity, and likewise for the striking differences between oscillations in $\mathrm{A}_{0^{-}}$and $\mathrm{C}$-neurons. Further studies will be required to determine the specific combination of biophysical characteristics responsible for oscillatory behavior in particular subtypes of DRG neurons.

\section{Increased oscillatory tendency after nerve injury}

Increased $\mathrm{Na}^{+}$conductance, caused by nerve injury-induced changes in the vectorial transport of $\mathrm{Na}^{+}$channels and/or $\mathrm{Na}^{+}$ channel upregulation, is implicated as a factor in the generation of neuropathic afferent discharge in animals and humans (Devor et al., 1994b; Matzner and Devor, 1994; Chaplan et al., 1995; England et al., 1996). The present results suggest that an underlying cause of this hyperexcitability is the enhanced oscillatory tendency of axotomized DRG neurons. The specific $\mathrm{Na}^{+}$conductance(s) involved is not known for certain. One likely candidate is the sustained TTX-sensitive $\mathrm{Na}^{+}$conductance (Rizzo et al., 1994; Baker and Bostock, 1997). This is partially activated at resting membrane potential in rat DRG neurons, is enhanced by modest depolarization, and is sensitive to $\mathrm{Na}^{+}$ion substitution, TTX, and lidocaine. Another possibility is the sustained window current ("m-h current") generated when the activation and inactivation functions of certain transient $\mathrm{Na}^{+}$conductances overlap in the voltage range that supports oscillatory behavior (Rizzo et al., 1996). A third candidate is the TTX-sensitive type III $\mathrm{Na}^{+}$ channel. This channel is virtually absent in intact DRG neurons in adult rats and hence is presumably not essential for baseline resonance. However, it may play a role in neuropathy because it is dramatically upregulated and its repriming kinetics are enhanced after axotomy (Waxman et al., 1994; Cummins and Waxman, 1997). It is not unlikely that the electrical phenotype of DRG neurons, and changes after axotomy, involve a combination of these channels.

The TTX-resistant $\mathrm{Na}^{+}$channels PN3/SNS and NaN/SNS2 are thought to play a special role in neuropathic pain because they are expressed selectively in DRG C-neurons (Akopian et al., 1996; Sangameswaran et al., 1996; Dib-Hajj et al., 1998; Tate et al., 1999). However, these transcripts are downregulated after nerve injury (Dib-Hajj et al., 1996, 1998; Cummins and Waxman, 1997), just as the excitability of the C-neurons is increased. Moreover, we found that TTX $(1 \mu \mathrm{M})$ blocked subthreshold oscillations and spiking in $\mathrm{C}$-neurons. It should be noted, however, that C-neurons also express TTX-sensitive $\mathrm{Na}^{+}$channel types. TTXsensitive and TTX-resistant $\mathrm{Na}^{+}$currents summate, determining nociceptor excitability jointly. Therefore, it is entirely possible that a selective PN3/SNS or NaN/SNS2 antagonist, if one could be developed, would suppress oscillations and ectopic discharge in $\mathrm{C}$-neurons. Such an agent might prove to be a uniquely useful pain reliever if it indeed acted selectively in the peripheral nerve and were devoid of side effects associated with blockage of CNS, muscle, and cardiac $\mathrm{Na}^{+}$channels.

\section{Oscillations and repetitive discharge in injured axons}

We recorded from afferent neuron somata. However, the behavior of the DRG soma is often mirrored, at least in part, in the behavior of the axon end (Reeh and Wadell, 1990; Harper, 1991). 
Consistent with this, ectopic discharge generated in nerve end neuromas takes the same patterns as that generated in DRG somata and is likewise selectively blocked by low concentrations of TTX and lidocaine (Devor et al., 1992; Matzner and Devor, 1994). It is therefore possible that ectopic neuroma firing is also subserved by membrane potential oscillations associated with a TTX-sensitive $\mathrm{Na}^{+}$conductance. Indeed, Kapoor et al. (1997) demonstrated that ectopic firing originating in primary afferent axons at sites of demyelination is triggered by intrinsic TTXsensitive membrane potential oscillations. Oscillatory membrane properties may be a general characteristic of afferent neurons capable of sustained discharge, both injured axons and the peripheral receptor ending of intact slowly adapting afferent types.

\section{Relation of subthreshold oscillations to neuropathic pain}

Because DRG neurons rarely fire at resting membrane potential and the DRG is essentially devoid of synaptic input, what could induce the depolarizing shift required to enhance oscillations and trigger ectopic discharge, paraesthesias, and pain? In fact, there are a number of nonsynaptic processes capable of doing this. Probably the most important is the biomechanical strain delivered to sensory neurons during movement or straight-leg lifting (Wall and Devor, 1983; Nordin et al., 1984; Kuslich et al., 1991). In addition, cross-depolarization induced in DRG neurons by spike activity in their neighbors can induce ectopic spiking (Devor and Wall, 1990; Amir and Devor, 1996), as can adrenergic agonists and sympathetic efferent activity (Devor et al., 1994a; Petersen et al., 1996). Indeed, we have preliminary evidence that the discharge evoked by these conditions is caused by the triggering or enhancement of oscillations. Slow, tonic depolarizing factors lead to the generation of repetitive discharge only in neurons that are primed for repetitive firing by virtue of their intrinsic oscillatory characteristics. Nerve pathology appears to increase ectopic firing primarily by enhancing oscillations. Oscillatory behavior in afferent neurons can be thought of as a motor ready to be engaged when the clutch of a slow-onset physiological depolarization is released. Mechanical stress, cross-depolarization, and sympathetic activity are all associated clinically with the exacerbation of neuropathic sensory symptoms (Sunderland, 1978; Bonica, 1990; Rappaport and Devor, 1994).

Axotomy induced an increase in the oscillatory behavior and spike discharge of both $\mathrm{A}_{0}$ and $\mathrm{C}$-neurons, although the change in $\mathrm{C}$-neurons did not reach statistical significance. However, even if the putative effect in $\mathrm{C}$-neurons were discounted, the increased excitability of $\mathrm{A}_{0}$-neurons can account not only for neuropathic paraesthesias and dysaesthesias but also for frank pain. The low level ectopic $\mathrm{C}$-fiber barrage generated in neuromas and axotomized DRGs is believed to be sufficient to trigger and maintain central sensitization. In the presence of central sensitization, input on large diameter myelinated afferents, notably $\mathrm{A}_{0}$-neurons, can generate pain sensation (Gracely et al., 1992; Torebjork et al., 1992; Sheen and Chung, 1993). Several additional processes triggered by nerve injury are also believed to be capable of rendering spike activity in $\mathrm{A}_{0}$-neurons painful. These include spinal disinhibition and the sprouting of low-threshold afferent endings into superficial layers of the dorsal horn (Devor 1988; Woolf et al., 1992). It should make no difference whether this $A_{0}$ activity originates in intact cutaneous sensory endings or ectopically in the DRG. Our observations, therefore, implicate the oscillatory behavior of primary afferent neurons as a fundamental factor in the generation of ectopic afferent firing and hence in the devel- opment of neuropathic pain states. Correspondingly, the oscillatory mechanism may provide targets for development of novel drugs for the treatment of chronic neuropathic pain.

\section{REFERENCES}

Akopian AN, Sivilotti L, Wood JN (1996) A tetrodotoxin-resistant voltage-gated sodium channel expressed by sensory neurons. Nature 379:257-262.

Alonzo A, Klink R (1993) Differential electroresponsiveness of stellate and pyramidal-like cells of medial entorhinal cortex layer II. J Neurophysiol 70:144-157.

Amir R, Devor M (1996) Chemically mediated cross-excitation in rat dorsal root ganglia. J Neurosci 16:4733-4741.

Amir R, Devor M (1997) Spike-evoked suppression and burst patterning in dorsal root ganglion neurons. J Physiol (Lond) 501:183-196.

Baker MD, Bostock H (1997) Low-threshold, persistent sodium current in large dorsal root ganglion neurons in culture. J Neurophysiol 77:1503-1513.

Bonica JJ (1990) Management of pain, Ed 2. Philadelphia: Lea \& Febiger.

Campbell JN, Raja SN, Meyer RA, MacKinnon SE (1988) Myelinated afferents signal the hyperalgesia associated with nerve injury. Pain 32:89-94.

Chaplan SR, Bach FW, Shafer SL, Yaksh TL (1995) Prolonged alleviation of tactile allodynia by intravenous lidocaine in neuropathic rats. Anesthesiology 83:775-785.

Cummins TR, Waxman SG (1997) Downregulation of tetrodotoxinresistant sodium currents and upregulation of a rapidly repriming tetrodotoxin-sensitive sodium current in small spinal sensory neurons after nerve injury. J Neurosci 17:3503-3514.

Devor M (1983) Potassium channels moderate ectopic excitability of nerve-end neuromas in rats. Neurosci Lett 40:181-186.

Devor M (1988) Central changes mediating neuropathic pain. In: Pain research and clinical management, Vol 3, Proceedings of the Vth World Congress on Pain (Dubner R, Gebhart GF, Bond MR, eds), pp 114128. Amsterdam: Elsevier.

Devor M (1994) The pathophysiology of damaged peripheral nerve. In: Textbook of pain, Ed 3 (Wall PD, Melzack R, eds), pp 79-100. London: Churchill-Livingston.

Devor M, Wall PD (1990) Cross excitation among dorsal root ganglion neurons in nerve injured and intact rats. J Neurophysiol 64:1733-1746.

Devor M, Wall PD, Catalan N (1992) Systemic lidocaine silences ectopic neuroma and DRG discharge without blocking nerve conduction. Pain 48:261-268.

Devor M, Janig W, Michaelis M (1994a) Modulation of activity in dorsal root ganglion (DRG) neurons by sympathetic activation in nerveinjured rats. J Neurophysiol 71:38-47.

Devor M, Lomazov P, Matzner O (1994b) $\mathrm{Na}^{+}$channel accumulation in injured axons as a substrate for neuropathic pain. In: Touch, temperature and pain in health and disease (Boivie J, Hansson P, Lindblom U, eds), pp 207-230. Seattle: Wenner-Gren Center Foundation Symposia, IASP Press.

Dib-Hajj S, Black JA, Felts P, Waxman SG (1996) Down-regulation of transcripts for $\mathrm{Na}+$ channel alpha-SNS in spinal sensory neurons following axotomy. Proc Natl Acad Sci USA 93:14950-14954.

Dib-Hajj SD, Tyrrell L, Black JA, Waxman SG (1998) NaN, a novel voltage-gated $\mathrm{Na}^{+}$channel preferentially in peripheral sensory neurons and down-regulated after axotomy. Proc Natl Acad Sci USA 95:8963-8968

England JD, Happel LT, Kline DG, Gamboni F, Thouron CL, Liu ZP, Levinson SR (1996) Sodium channel accumulation in humans with painful neuromas. Neurology 47:272-276.

Getting PA (1989) Emerging principles governing the operation of neural networks. Annu Rev Neurosci 12:185-204.

Gracely RH, Lynch SA, Bennett GJ (1992) Painful neuropathy: altered central processing maintained dynamically by peripheral input. Pain 51:175-194.

Gutfreund Y, Yarom Y, Segev I (1995) Subthreshold oscillations and resonant frequency in guinea-pig cortical neurons: physiology and modelling. J Physiol (Lond) 483:621-640.

Guttman R, Barnhill R (1972) Oscillation and repetitive firing in squid axons. J Gen Physiol 55:104-118.

Harper AA (1991) Similarities between some properties of the soma and sensory receptors of primary afferent neurones. Exp Physiol 76:369-377. 
Hutcheon B, Miura RM, Puil E (1996) Subthreshold membrane resonance in neocortical neurons. J Neurophysiol 76:683-697.

Jack JJB, Noble D, Tsien RW (1985) Repetitive activity in excitable cells. In: Electric current flow in excitable cells, pp 305-378. Oxford: Clarendon.

Kapoor R, Li Y-G, Smith KJ (1997) Slow sodium-dependent potential oscillations contribute to ectopic firing in mammalian demyelinated axons. Brain 120:647-652.

Kingery WS, Vallin JA (1989) The development of chronic mechanical hyperalgesia, autotomy and collateral sprouting following sciatic nerve section in rat. Pain 38:321-332.

Koerber HR, Mendell LM (1992) Functional heterogeneity of dorsal root ganglion cells. In: Sensory neurons (Scott SA, ed), pp 77-96. New York: Oxford.

Kuslich SD, Ulstrom CL, Michael CJ (1991) The tissue origin of low back pain and sciatica. Orthop Clin North Am 22:181-187.

Llinas R (1988) Insights into central nervous system function: the intrinsic electrophysiological properties of mammalian neurons. Science 242:1654-1664.

Markus H, Pomerantz B, Krushelnychy D (1984) Spread of saphenous somatotopic projection map in spinal cord and hypersensitivity of the foot after chronic sciatic denervation in adult rat. Brain Res 296:27-39.

Matzner O, Devor M (1994) Hyperexcitability at sites of nerve injury depends on voltage-sensitive $\mathrm{Na}^{+}$channels. J Neurophysiol 72:349-357.

Nordin M, Nystrom B, Wallin U, Hagbarth K-E (1984) Ectopic sensory discharges and paresthesiae in patients with disorders of peripheral nerves, dorsal roots and dorsal columns. Pain 20:231-245.

Pelkey KA, Marshall KC (1998) Actions of excitatory amino acids on mesencephalic trigeminal neurons. Can J Physiol Pharmacol 76:900-908.

Petersen M, Zhang J, Zhang J-M, LaMotte RH (1996) Abnormal spontaneous activity and responses to norepinephrine in dissociated dorsal root ganglion cells after chronic nerve constriction. Pain 67:391-397.

Puil E, Spigelman I (1988) Electrophysiological responses of trigeminal root ganglion neurons in vitro. Neuroscience 24:635-646.

Puil E, Gimbarzevsky B, Miura RM (1986) Quantification of membrane properties of trigeminal root ganglion neurons in guinea pigs. J Neurophysiol 55:995-1016.

Puil E, Gimbarzevsky B, Spigelman I (1988) Primary involvement of K ${ }^{+}$ conductance in membrane resonance of trigeminal root ganglion neurons. J Neurophysiol 59:77-89.

Puil E, Miura RM, Spigelman I (1989) Consequences of 4-aminopyridine applications to trigeminal root ganglion neurons. J Neurophysiol 62:810-820.

Puil E, Meiri H, Yarom Y (1994) Resonant behavior and frequency preferences of thalamic neurons. J Neurophysiol 71:575-582.

Rappaport ZH, Devor M (1994) Trigeminal neuralgia: the role of selfsustaining discharge in the trigeminal ganglion (TRG). Pain 56:127-138.

Reeh PW, Wadell PJ (1990) A comparison of the adaptation of rat cutaneous sensory receptors and their cell bodies in vitro. J Physiol (Lond) 420:109P.

Rizzo MA, Kocsis JD, Waxman SG (1994) Slow sodium conductances of dorsal root ganglion neurons: intraneural homogeneity and interneuronal heterogeneity. J Neurophysiol 72:2796-2815.

Rizzo MA, Kocsis JD, Waxman SG (1996) Mechanism of paraesthesiae and hyperaesthesiae: role of $\mathrm{Na}^{+}$channel heterogeneity. Eur Neurol 36:3-12.

Roberts WM, Howard J, Hudspeth AJ (1988) Hair cells: transduction, tuning and transmission in the inner ear. Annu Rev Cell Biol 4:63-92.

Sangameswaran L, Delgado SG, Fish LM, Koch BD, Jakeman LB, Stewart GR, Sze P, Hunter JC, Eglen RM, Herman RC (1996) Structure and function of a novel voltage- gated, tetrodotoxin-resistant sodium channel specific to sensory neurons. J Biol Chem 271:5953-5956.

Selverston AI (1985) Oscillatory neural networks. Annu Rev Physiol 1847:29-48.

Sheen K, Chung JM (1993) Signs of neuropathic pain depend on signals from injured fibers in a rat model. Brain Res 610:62-68.

Study RE, Kral MG (1996) Spontaneous action potential activity in isolated dorsal root ganglion neurons from rats with a painful neuropathy. Pain 65:235-242.

Sunderland S (1978) Nerves and nerve injuries, Ed 2. London: Churchill Livingstone.

Tate S, Benn S, Hick C, Trezise D, John V, Mannion RJ, Costigan M, Plumpton C, Grose D, Gladwell Z, Kendall G, Dale K, Bountra C, Woolf CJ (1999) Two distinct sodium ion channels contribute to the tetrodotoxin-resistant sodium current in primary sensory neurons. Nat Neurosci 1:653-655.

Torebjork HE, Lundberg LER, LaMotte R H (1992) Central changes in processing of mechanoreceptive input in capsaicin-induced secondary hyperalgesia in humans. J Physiol (Lond) 448:765-780.

Utzschneider D, Kocsis J, Devor M (1992) Mutual excitation among dorsal root ganglion neurons in the rat. Neurosci Lett 146:53-56.

Villiere V, McLachlan EM (1996) Electrophysiological properties of neurons in intact rat dorsal root ganglia classified by conduction velocity and action potential duration. J Neurophysiol 76:1924-1941.

Wall PD, Devor M (1983) Sensory afferent impulses originate from dorsal root ganglia as well as from the periphery in normal and nerve-injured rats. Pain 17:321-339.

Wall PD, Devor M, Inbal R, Scadding JW, Schonfeld D, Seltzer Z, Tomkiewicz MM (1979) Autotomy following peripheral nerve lesions: experimental anaesthesia dolorosa. Pain 7:103-113.

Waxman SG, Kocsis JD, Black JA (1994) Type III sodium channel mRNA is expressed in embryonic but not adult spinal sensory neurons and is re-expressed following axotomy. J Neurophysiol 72:466-470.

Woolf CJ (1983) Evidence for a central component of post-injury pain hypersensitivity. Nature 306:686-688.

Woolf CJ, Shortland P, Coggeshall RE (1992) Peripheral nerve injury triggers central sprouting of myelinated afferents. Nature 355:75-78.

Xie Y, Zhang J, Petersen M, Lamotte RH (1995) Functional changes in dorsal root ganglion cells after chronic nerve constriction in the rat. J Neurophysiol 73:1811-1820.

Yarom Y (1989) Oscillatory behavior of olivary neurons. Exp Brain Res 17:209-220. 